\title{
The Evolution of China's High-Level Talent Mobility Network: A Comparative Analysis Based on School and Work Stage
}

\author{
Fangfang Zhang $\mathbb{D}^{1,2,3,4}$ Hui Liu $\mathbb{D}^{1,2,3}$ Juntao Zhang, ${ }^{5}$ and Yi Cheng $\mathbb{D}^{1,2,3}$ \\ ${ }^{1}$ Institute of Geographic Sciences and Natural Resources Research, Chinese Academy of Sciences, Beijing 100101, China \\ ${ }^{2}$ Key Laboratory of Regional Sustainable Development Modeling, Chinese Academy of Sciences, Beijing 100101, China \\ ${ }^{3}$ College of Resource and Environment, University of Chinese Academy of Sciences, Beijing 100049, China \\ ${ }^{4}$ Faculty of Geographical Science, Beijing Normal University, Beijing 100875, China \\ ${ }^{5}$ School of Computer Science, Wuhan University, Wuhan 430072, China \\ Correspondence should be addressed to Hui Liu; liuh@igsnrr.ac.cn
}

Received 24 September 2021; Revised 8 December 2021; Accepted 21 December 2021; Published 24 January 2022

Academic Editor: Giacomo Fiumara

Copyright (c) 2022 Fangfang Zhang et al. This is an open access article distributed under the Creative Commons Attribution License, which permits unrestricted use, distribution, and reproduction in any medium, provided the original work is properly cited.

\begin{abstract}
The flow of high-level talents in China is becoming more and more active and has a profound impact on the innovation and development of cities. Based on the research on the spatial distribution of the school and work stages of high-level talent in China, we study the structure and evolution of China's high-level talent mobility network by using the data on the flow trajectory of talent among cities in China. The results show that: (1) the spatial distribution of talents in the two stages has greater consistency, but there is a change characteristic of "large dispersion, small agglomeration." (2) Compared with the school stage, the network in the work stage has much more connections; the centrality gap of cities has narrowed. (3) "Core-periphery" structure of two networks is relatively significant and similar. The core layer in the two networks has not changed, but the subcore layer and the subedge layer have undergone changes. In addition, talents mainly flow to core and subcore cities. (4) The space structure of network is more complex in the work stage, and it is expanding to the Guangdong-Hong Kong-Macao Greater Bay Area in southeastern China.
\end{abstract}

\section{Introduction}

Talent has become a crucial strategic resource in China's economic and social development [1]. The spatial layout and flow efficiency of high-level talents (HLT) to a large extent characterize the regional economic development status [2] and represent the distribution of the engine of the science and technology industry [3]. Large-scale talent flow is bound to have a significant impact on China's regional innovation capabilities, economic system structure, industrial layout, population distribution structure, and social and cultural environment $[4,5]$. Therefore, studying the state of HLT is crucial to the overall understanding of innovation and economic development $[3,6]$.

At present, China's rapid technological innovation, increasing progress in transportation technology, fast development of information and communication technology, and the combined effect of multiple factors have provided great convenience for the flow of HLT across the country. At the same time, local governments have introduced a series of policies and measures to attract talents, which accelerate the flow of HLT. However, the unhealthy competition for talent introduction among cities has aggravated the irrational flow of talents, leading to an uneven regional distribution of talents. Issues such as "Peacocks Flying Southeast," "Crisis in the Midwest," and "Dilemma in the Northeast" have emerged in China [7]. In April 2017, the Ministry of Science and Technology issued the "Thirteenth Five-Year Plan for the Development of Scientific and Technological Talents" (Ministry of Science and Technology, PRC. The 13th Five-Year Plan for The Development of Scientific and technological Talents, 2017. 
Available at: http://www.casec.org.cn/article/show\% 20article.\%20asp?articleid $=728$ ), proposing to remove obstacles to the flow of talents and allow free flow of scientific and technological talents in accordance with market laws. In September 2021, General Secretary Xi Jinping pointed out at the Central Conference on Talent work (http://www.gov.cn/xinwen/2021-09/28/content_ 5639868.htm?version=2.5.40020.452 \&platform $=$ win) that Beijing, Shanghai, and the Guangdong-Hong Kong-Macao Greater Bay Area could be built into HLT hubs, and some central cities with HLT concentration should also focus on building platforms to attract and gather talent. Factors such as regional development differences, unhealthy talent competition among cities, and government policy guidance will inevitably have an important impact on the flow of HLT in China. In this context, there is an urgent need to thoroughly study the spatial distribution and flow characteristics of China's HLT, so as to provide support for the government to formulate scientific policies for attracting talents.

In recent years, the study of talent flow in China has become a hot topic. Relevant researches mainly focus on the current situation of talent flow [8-10], model of talent flow $[11,12]$, influencing factors of talent flow [13], and the impact of talent flow on scientific research output [14]. Although scholars have studied talent flow in China, there are still some problems that need to be remedied. First, there is a lack of quantitative research on the domestic flow of HLT in China. Due to the limitation of data acquisition, the study of HLT flow in China has always been a difficult problem. Most of the existing quantitative studies only studied the geographical flow characteristics of a specific type of talents (academicians, outstanding young scholars, or Changjiang scholars) $[8,9,15]$. These studies have great limitations, and the results cannot represent the flow of HLT in China in a broader sense $[9,15,16]$. Second, few studies analyzed and compared talent flow from the growth stage of talent [17]. Due to the distribution of national education and work resources, regional development, and individual factors of talents, the flow of talents in the stage of education and work has different characteristics, and the reasons and mechanisms of the flow are also different. Therefore, it is of great practical significance to study the characteristics of the flow of HLT among cities. It can also enrich the relevant researches on the flow of talents in China and provide reference for the formulation of talent attraction policies for cities in China.

This article aims to compare and analyze the spatial distribution, flow characteristics, and differences of China's HLT in the school and work stage. The article has six parts. The first part is introduction. The second part reviews the relevant research on the flow of HLT in China and discusses how to study the flow of HLT based on the theory of networks and mobility spaces. The third part introduces the data sources and research methods. The fourth part is the result analysis, which is elaborated from four aspects: the spatial distribution characteristics of HLT, the changes in the basic attributes of the talent flow network, and the changes in the "core-edge" structure and spatial structure of the talent flow network. The fifth part further discusses the changing characteristics of the spatial distribution of talents, the characteristics of talent mobility (bidirectional, stickiness, and Matthew effect), and the spatial heterogeneity of talent mobility networks. Finally, the main conclusions and contributions of this article are briefly summarized.

\section{Space of Flows, Network, and Talent Flow}

The concept of "flow" has emerged in the context of economic globalization and informatization, which are reshaping the organization structure of the world-what Castells calls "the rise of network society" [18]. The salient feature of this new organizational structure is the dominant position of various "flows," such as population flow, information flow, capital flow, and technology flow. "Flow" and "space" are inseparable. Manuel Castells proposed that "space of flows" means "physical organization of social practices that share time without geographical adjacency" [19]. Its structure consists of four parts: "(1) It is made up of a technological infrastructure of information systems, telecommunications, and transportation lines. (2) The space of flows is made up of nodes and hubs. (3) The space of flows is also made of habitats for the social actors that operate the networks. (4) The space of flows comprises electronic spaces" [20].

Ma summarized and proposed that "flow" in various forms between cities is a "soft network" (which can be divided into economic, political, social, and cultural connection functions) based on the "hard network" (such as highway, railway, airport, telecommunications, and other infrastructure) between cities, which are expressed in multiple forms of connection among human, materials, and information [21-23]. Talent mobility network between cities can be regarded as "soft network" based on "hard network." Talent flow is always associated with specific cities [24]. As the main place of knowledge innovation and technology diffusion, city is one of the important network nodes, which belongs to the second part of the structure of "space of flows."

At the end of the 20th century, the complex network theory based on mathematical graph theory and statistical physics provided a theoretical basis for studying the complexity of network systems [25-27]. Complex network theory and methods have been used in many fields such as disease transmission [28], transportation networks [29], scientific research cooperation networks [30], and urban networks [31, 32]. This method also provides a new perspective for the identification of talent flow network structure. It usually abstracts the overall flow of talents into a network and applies network analysis methods to carry out related research. With the development of big data technology, the data of "talent flow" have become available. Scholars have begun to try to collect information on the flow of talents online, mining trajectory data of talents from the resume, published papers, patents, and other information at various stages of learning, work, etc. [33]. On the basis of big data mining, scholars usually apply various characteristics and indicators of complex networks to the relevant analysis of talent flow networks. For example, there is a network of 
the talent flow composed of scientific research leaders [27], scientists [34], corporate talents [35, 36], overseas students [37], and returned talents [38].

There have been studies using the talent flow network to explore the spatial characteristics and trends of talent flow, and to predict and simulate the trend of talent flow. Fagiolo and Mastrorillo obtained relevant conclusions about the trends and characteristics of global migration in the world today by studying international migration networks and predicted the trend of international migration in the future [39]. Wang et al. [40,41] constructed a global technology leader talent flow network model to measure and analyze the characteristics of the global technology leader talent flow in major countries (regions) and the world as a whole. Zhu Pengcheng [36] conducted research on the geographical network of talent flow in the Yangtze River Delta and explored the direction and activity of talent flow in the network. Shi Wentian [34] found that Beijing and Shanghai located in the core area of the scientific research cooperation network of Chinese scientists.

In addition, scholars have also begun to portray different types of urban networks or innovation networks in terms of talent flow. In the era of knowledge economy, the importance of human capital in economic and social development has become increasingly prominent, and the flow and agglomeration of talents has become an important driving force for the evolution of the world's urban network system and the development of global cities. In the study of the world city network based on the flow of "highly skilled international migrants" $[42,43]$, scholars believe that the processes of talent management and global staffing are nourishing the knowledge base of world cities. It provides a continuous flow of talents for these places, ensuring that they achieve a high ranking in the global city hierarchy [43]. Moreover, using talent mobility to build innovative relationships between cities can better reflect the connection of tacit knowledge than papers and patents, and HLT can reflect the high-level part of tacit knowledge, which has an important value for simulating the flow of high-level knowledge and innovative connections between cities [21]. Relevant studies have found that HLT can also establish important knowledge connections for cities where they live, study, or work for a long period of time, and built innovation network between cities by using China's “Thousand Talents Plan" talents and important entrepreneurs' migration [38].

Network science and methods provide a strong support for the research on the structural characteristics and evolution of talent regional flow network. This paper tries to use the talent flow network to answer the following three core questions: first, compare the characteristics of node attributes in the talent flow network and analyze the characteristics of talent flow between cities. Second, by comparing the core-edge structure of the network, this paper discusses whether there is Matthew effect in the current flow of HLT in China. Third, the spatial heterogeneity of talent flow network is analyzed by comparing its spatial structure.

\section{Data and Methods}

3.1. Definition of High-Level Talents and Data Sources. According to the definition of talents in talent science, talents are people who have certain knowledge and skills under certain historical conditions and use their creative work to make greater contributions to society or a certain aspect of society [44]. HLT usually refers to a small number of academic elites who produce knowledge, enjoy a high reputation, and lead the development of disciplines [45]. Chinese city governments have slightly different identification systems for HLT, but they generally divide talents into three categories: domestic and foreign top talents, nationallevel leading talents, and local-level leading talents. At present, a number of high-level academic groups have formed, including academicians of the Chinese Academy of Sciences and Chinese Academy of Sciences, Changjiang Scholars, Outstanding young people, and so on. Considering the availability of data, the HLT in this article refers to the academicians of the Chinese Academy of Sciences (ACAS), the academicians of the Chinese Academy of Engineering (ACAE), the Chinese academicians of the International Eurasian Academicians (IAEA), the Chinese academicians of the Academicians of Developing Countries (TWAS), the scholar of the Changjiang Scholars Program (CJSP), and the scholar of the National Outstanding Youth Fund Project (NOYFPS).

The election of the academicians of the CAS began in 1955. The earliest year of the academicians still living in the datais 1980. The election of the CAE began in 1994, and the earliest year of the living academicians is 1994. The earliest Chinese academicians of IAEA and TWAS, still alivingis 1994 and 1983, respectively. The Changjiang Scholars Program was established in 1998, and the National Science Fund for Outstanding Youths was established in 1994. Therefore, the research period of this article is 1980-2020.

The talent data in this paper are all obtained from the official website. Among them, the data of ACAS are obtained from the official website of the Chinese Academy of Sciences (http://casad.cas.cn/ysxx2017/ysmdyjj/qtysmd_124280/), with a total of 812 talents. The data of ACAE are obtained from the official website of the Chinese Academy of Engineering (https:/www.cae.cn/cae/html/main/col48/column_

48_1.html), with a total of 911 talents. The IAEA and TWAS were obtained from the official website (http://bj.ieaschina. org/expert/jieshao.html; https:/www.cas.cn/zt/hyzt/twas23/ abouttwas/201208/t20120808_36\%2025109.html), respectively, with a total of 378 talents. The source of the information on the CJSP is with the Ministry of Education of the People's Republic of China (http://www.moe.gov.cn/jyb_xxgk/s5743/ $s 5745 /$ ), with a total of 3143 talents. The data of NOYFPS came from the National Natural Science Foundation of China (https://www.nsfc.gov.cn/), with a total of 4303 talents. Because some talents have multiple titles at the same time, this article merges the data of such talents into one sample. For example, if a scientist has successively obtained the titles of CJSP, TWAS, and ACAS, then we will retain the last title of ACAS for this scientist, but his data information contains the titles of CJSP and TWAS. In addition, this article does not 
include foreign talents from 1980 to 2020. In the end, this article collected information on 7734 talents.

3.2. Talent Flow Trajectory Data Processing. The research area of this article is China (as some talents have study or work experience in Hong Kong, Macau, Taiwan, and other regions, the above regions are also included in this research), and the basic research unit is prefecture-level cities. The talent flow trajectory data are mainly judged by the change of the working city. If the working city of the talent changes, we judge that the talent flow has occurred $[8,41]$. The specific steps are as follows: (1) Define the city of the talent's first school as the "first city of school" and then count the city where the school is located in chronological order. When the city changes, it is defined as the "second, third, ..., school city" of the talent. On this basis, determine the talent flow trajectory based on prefecture-level cities (first school city $\longrightarrow$ second school city $\longrightarrow$ third school city, etc.). If the city where the talent school is located has not changed, it will not be included in the flow trajectory. (2) Define the city of the talent's first workplace as the "first city of workplace" and then count the city where the workplace is located in chronological order. When the city changes, it is defined as the "second, third, ... city of workplace" of the talent. On this basis, determine the talent flow trajectory based on prefecture-level cities (first city of workplace $\longrightarrow$ second city of workplace $\longrightarrow$ third city of workplace, etc.).

3.3. Network Construction. Drawing lessons from network graphics and matrix expression methods, create the talent flow network of this article $[27,46]$. The talent flow network is a directed complex network. In this paper, cities are regarded as nodes in the network, and the direction of talent flow is regarded as edges. To build a networked model, talent flow is along the direction of the edges between nodes (Figure 1). To construct a network matrix of talent flow between cities, the ordinate of the matrix is set as the outflow city, and the inflow city is set as the abscissa of the matrix. The value of the element in the matrix is the number of highlevel talents flowing from the out-flow city to the in-flow city.

\subsection{Centrality Analysis of Network Nodes}

3.4.1. Degree Centrality. This refers to the number of other nodes directly connected to the target node in the network and represents the degree of node connection [46]. In this article, the degree centrality of a node indicates the number of cities that have a talent flow connection with the city. Degree centrality is divided into in-degree centrality and out-degree centrality. Among them, the in-degree centrality can reflect the centrality of a city as a city for attracting talents in the talent flow network. The out-degree centrality reflects the centrality of a city as a talent outflow city in the talent flow network [47]. It is calculated as follows:

$$
C_{D}(i)=\sum_{j=1, j \neq i}^{n} k_{i j}+\sum_{j=1, j \neq i}^{n} k_{j i} .
$$

Here, $C_{D}(i)$ is the degree centrality of the node, which refers to the number of other nodes connected to the node $i$, $k_{i j}$ represents the outflow of the node, and $k_{j i}$ represents the inflow of the node.

3.4.2. Strength Centrality. This refers to the sum of the weights of the edges formed by all other nodes associated with a node in the network [48, 49]. It represents the connection scale of nodes in the network. In this paper, strength centrality is the sum of the flow of talents between a certain city and all other cities:

$$
S_{i}=\sum_{j=1, j \neq i}^{N} C_{i j}
$$

Here, $S_{i}$ is the strength centrality of city $i$, that is, the sum of the flow of city $i$ and other cities; $j$ is the other cities connected to city $i ; N$ is the number of cities; and $C_{i j}$ is the flow quantity of talent between city $i$ and city $j$.

3.4.3. Betweenness Centrality. This measures how much a point lies "in the middle" of other points in the graph. If a point is on the shortcut of other point pairs, we say that the point has a high intermediate centrality [46]. The calculation formula for the centrality of the directed network is as follows:

$$
C_{B}(i)=\frac{1}{2} \sum_{j}^{n} \sum_{k}^{n} \frac{g_{j k}(i)}{g_{j k}}, \quad j \neq k \neq i, \text { and } j<k,
$$

where $g_{j k}$ is the number of shortest paths used to connect point $j$ and point $k$ and $g_{j k}(i)$ is the number of shortest paths through point $i$ between point $j$ and point $k$.

3.4.4. Comprehensive Centrality [30]. The first three node centrality indicators in the article all measure the rights of nodes in the network from a single aspect and lack the comprehensive centrality measurement of the connections between nodes. Therefore, this article draws on the comprehensive centrality model to comprehensively evaluate each node, which is calculated as follows:

$$
z_{i}=\rho_{1} \times \operatorname{Stand}\left(C_{D}\right)+\rho_{2} \times \operatorname{Stand}\left(S_{i}\right)+\rho_{3} \times \operatorname{Stand}\left(C_{B}\right) \text {, }
$$

where $z_{i}$ is the comprehensive centrality and Stand $\left(C_{D}\right)$, Stand $\left(S_{i}\right)$, and $\operatorname{Stand}\left(C_{B}\right)$ are the standardized values of degree centrality, strength centrality, and betweenness centrality, respectively. $\rho_{1}, \rho_{2}$, and $\rho_{3}$ are the weights of the three indicators, respectively. This article believes that the three indicators are equally important, so the weights are all set to $1 / 3$.

\subsection{Network Visualization Method}

3.5.1. Visualization of Core-Edge Structure. Based on the value of comprehensive centrality, this paper uses the Jenks method (a method of classification) to divide the network 


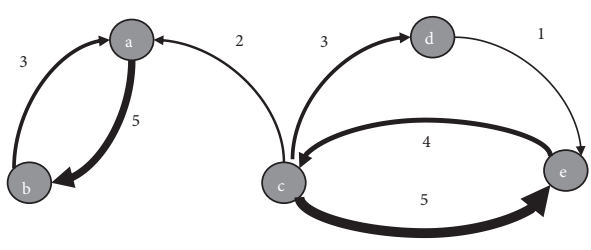

Multivalued directed graph

\begin{tabular}{|c|c|c|c|c|c|}
\hline $\begin{array}{c}\text { Out flow }_{\text {In }}^{\text {flow }} \\
\text { flow }\end{array}$ & $\mathrm{a}$ & $\mathrm{b}$ & $\mathrm{c}$ & $\mathrm{d}$ & $\mathrm{e}$ \\
\hline $\mathrm{a}$ & 0 & 5 & 0 & 0 & 0 \\
\hline $\mathrm{b}$ & 3 & 0 & 0 & 0 & 0 \\
\hline $\mathrm{c}$ & 2 & 0 & 0 & 3 & 5 \\
\hline $\mathrm{d}$ & 0 & 0 & 0 & 0 & 1 \\
\hline $\mathrm{e}$ & 0 & 0 & 4 & 0 & 0 \\
\hline
\end{tabular}

Multivalued directed network matrix

FIgURE 1: Multivalued network graph and multivalued network matrix.

into four levels of "core, subcore, subedge, and edge" and draw it with the help of Ucinet, Pajek. The color of the city nodes in Figure 2 represents the different levels of comprehensive centrality. Because there are too many city nodes, the city structure diagram only shows the core layer, the subcore layer, and the subedge layer.

3.5.2. Visualization of Space Structure. Taking the flow trajectory of talent between cities as the core connection of the provincial talent mobility network, this paper draws the spatial structure of the talent mobility network by using ArcGIS. The size of the node in Figure 3 indicates the number of talent flowing through the city. The larger the node, the more mobile talents. The thickness of the edge in Figure 3 indicates the amount of mobility between the two cities. The thicker the edge, the more the amount of mobility.

\section{Results}

4.1. Spatial Distribution and Flow of HLT. The distribution of talents in China has always shown a strong spatial imbalance [50]. At the school stage, the HLT are distributed in 141 cities (Figure 4), with an average of 97 talents in each city. There are 22 cities above average, and the top 10 cities are Beijing, Shanghai, Nanjing, Wuhan, Xi'an, Hefei, Hangzhou, Harbin, Changchun, and Tianjin. There are 212 cities where HLT in China are located in Figure 4, with an average of 63 talents in each city. There are 24 cities exceeding the average, and the top 10 cities are Beijing, Shanghai, Nanjing, Wuhan, Guangzhou, Hong Kong, Xi'an, Hangzhou, Hefei, and Tianjin. Cities that attract HLT to choose jobs are mainly located in the east of China, followed by the central region, and very few in the west.

Comparing the spatial distribution of talents, the spatial distribution of talents in the work stage has been significantly expanded. However, the spatial distribution of talents in the two stages is still relatively consistent. They are mainly distributed in the eastern part of China, along the Yangtze River valley, and central and western provincial capital cities. These cities are also the main locations of China's 985 and 211 universities (Figure 4). It can be seen that this spatial distribution of HLT is closely related to the spatial distribution of national universities, laboratories, and innovation platforms.
The data show that at the school stage, 2047 talents (26.47\%) moved once, that is, they changed to a master's or doctoral school; 303 people (3.92\%) moved twice, that is, both master and doctoral schools changed. In comparison, a total of 2,348 people moved during the work stage. The highest number of flows reached 9 times. Among them, 2914 people (22.12\%) moved 1 time; 1365 people $(17.65 \%)$ moved twice; and 566 people moved 3 times or more (37.68\%). From the school stage to the work stage, the number of talent flows increased from 2,653 to 4341, and the flow of talents became more active. However, cities with a large amount of talent flow are concentrated in a few cities (Table 1). The results show that the top five city pairs for the flow of HLT during the school stage are Wuhan $\longrightarrow$ Beijing, Nanjing $\longrightarrow$ Beijing, Xi'an $\longrightarrow$ Beijing, Hefei $\longrightarrow$ Beijing, and Shanghai $\longrightarrow$ Beijing. The top five cities for the flow of high-level talents at the work stage are Beijing $\longrightarrow$ Shanghai, Beijing $\longrightarrow$ Hong Kong, Shanghai $\longrightarrow$ Beijing, Hong Kong $\longrightarrow$ Beijing, and Beijing $\longrightarrow$ Wuhan.

\subsection{Node Centrality of the Network}

4.2.1. Degree Centrality. In the school stage, Beijing has the highest indegree centrality, followed by Shanghai. The indegrees of the top 15 cities are all greater than the outdegree (Figure 5). These cities have high-quality educational resources and are favored by talent. At the work stage, Beijing's indegree is still the highest, but Beijing's outdegree and indegree are almost the same. Beijing's high housing prices and competitive pressure may have contributed to the outflow of some young talents. In addition, some talents work part time in areas outside Beijing, which makes Beijing's outdegree relatively high. The outdegree of Changsha and Harbin is higher than the indegree, and they are the cities with more serious brain drain in China. In contrast, first-tier cities such as Beijing, Shanghai, Guangzhou, Nanjing, Wuhan, and Hangzhou all have higher indegree than outdegree and are key cities for absorbing talent.

4.2.2. Strength Centrality. The results (Figure 6) show that in the school stage, the strength centers of cities such as Beijing, Shanghai, Nanjing, and Wuhan are at the forefront, indicating that these cities are the preferred cities for talent in the process of studying. Moreover, these cities are regions with extremely rich educational resources, which promotes the frequent flow of talents between these cities. Although 


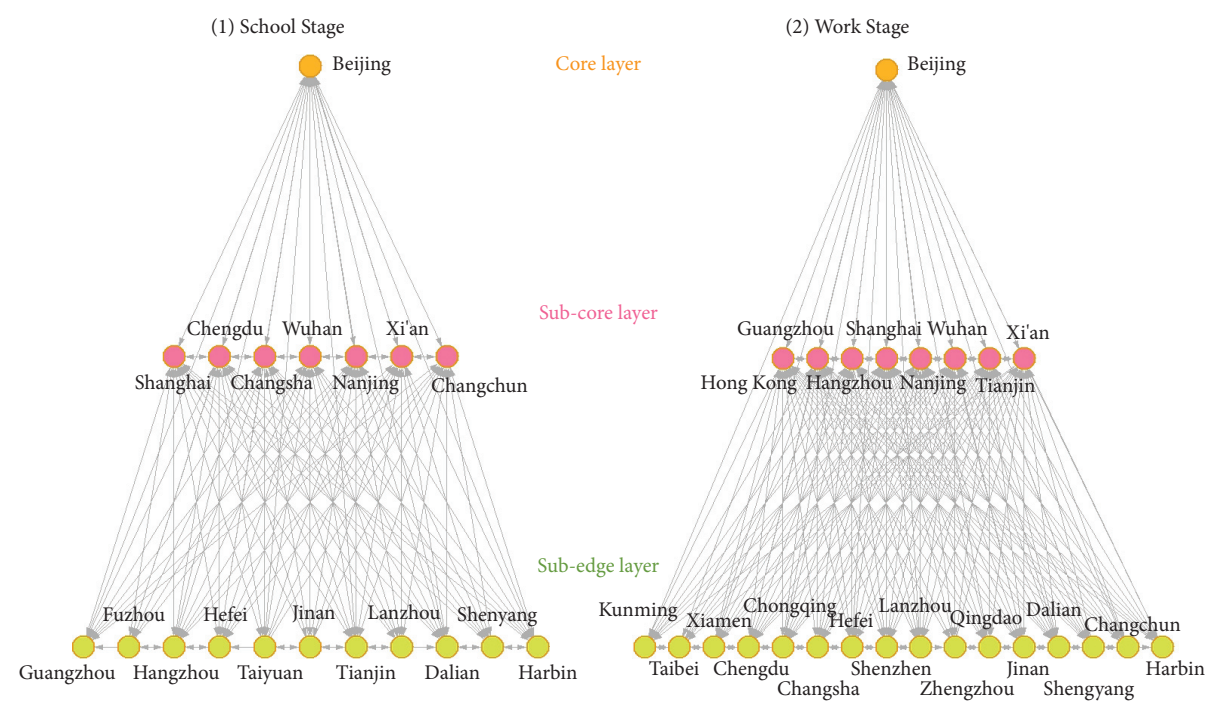

FIgURE 2: Hierarchical structure diagram of the talent mobility network.

TABLe 1: Top 10 city pairs of the number of talent flows.

\begin{tabular}{lccccc}
\hline & \multicolumn{2}{c}{ School stage } & & \multicolumn{2}{c}{ Work stage } \\
Outflow city & Inflow city & The number of talent flows & Outflow city & Inflow city & The number of talent flows \\
\hline Wuhan & Beijing & 115 & Beijing & Shanghai & 121 \\
Nanjing & Beijing & 83 & Beijing & Hong Kong & 85 \\
Xi'an & Beijing & 62 & Shanghai & Beijing & 65 \\
Hefei & Beijing & 60 & Hong Kong & Beijing & 62 \\
Shanghai & Beijing & 59 & Beijing & Wuhan & 57 \\
Changchun & Beijing & 52 & Beijing & Guangzhou & 56 \\
Chengdu & Beijing & 51 & Beijing & Nanjing & 56 \\
Jinan & Beijing & 51 & Wuhan & Beijing & 56 \\
Lanzhou & Beijing & 44 & Beijing & Hefei & 51 \\
Nanjing & Shanghai & 43 & Nanjing & Beijing & 50 \\
\hline
\end{tabular}

Guangzhou has a high degree of centrality, its strength centrality is low. Compared with cities such as Beijing, Shanghai, Wuhan, and Nanjing, Guangzhou's educational resources are relatively weak. In the work stage, Beijing's strength centrality is still the highest, and the number of connections in Beijing is almost the total number of connections in Shanghai, Nanjing, Wuhan, Xi'an, and Hangzhou. In addition, despite the massive increase in the number of nodes in the network during the work phase, there are only 21 cities with a strength centrality higher than 100 , which shows that the destination of talent flow has a strong agglomeration.

4.2.3. Betweenness Centrality. In the school stage, the ranking of the centrality of cities is quite different. Cities such as Beijing, Shanghai, Nanjing, Wuhan, and Xi'an have relatively high betweenness centrality, and they have a strong ability to control the resources in the network. As an important gathering place for educational resources, these nodes play an intermediary role. During the work stage, Beijing's centrality is extremely high, indicating that no matter whether it outflows or inflows, a larger part of the work place of talent includes Beijing.
From the stage of school to the stage of work, the scale of the network has expanded greatly. The number of city nodes in the network has increased from 142 to 216 . From the perspective of the changes in node centrality (Figure 6), the nodes and their projections are relatively scattered, and the centrality of each node has a large gap during the school stage. During the work stage, the centrality of Beijing and Shanghai is still much higher than that of other cities. However, other city nodes have become more concentrated, the centrality gap between nodes has narrowed, indicating that the network is more mature in the work stage, and the role of city nodes is more prominent.

\subsection{Core-Edge Structure of Network}

4.3.1. School Stage (Figure 2). (1) Core layer: Beijing. As a national science and technology innovation center, Beijing has the largest number of universities and research institutions in China, attracting a large number of high-level talents, becoming the core of the network, and occupying a dominant position in the network. And the resources of the edge layer continue to flow to the core, which will further strengthen the position of the core node. (2) Subcore layer: 


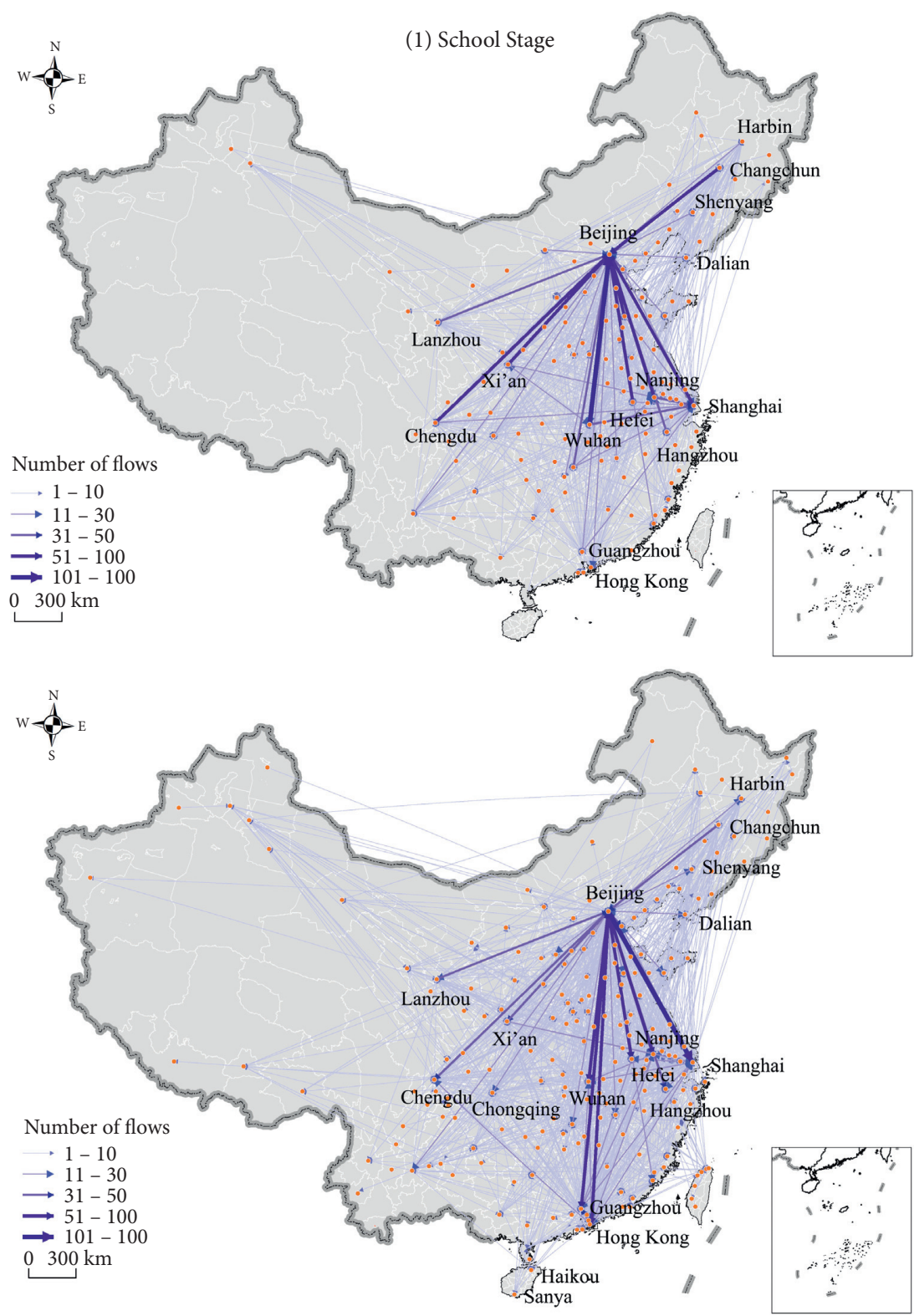

Figure 3: Changes in the spatial structure of the talent mobility network. (a) School stage. (b) Work stage.

Shanghai, Nanjing, Chengdu, Wuhan, Xi'an, Changchun, and Changsha. As the secondary core, cities in this level are closely connected to other cities. (3) Subedge layer: Lanzhou, Hefei, Harbin, Dalian, Tianjin, Taiyuan, Guangzhou, Hangzhou, Shenyang, Jinan, and Fuzhou. Although the average comprehensive centrality of this level of nodes is not as high as that of the first two levels, it is also a relatively important node for leading the connections between cities of different levels. (4) Edge layer: Shangrao, Dongying, Linfen, Linyi, and Urumqi and other 123 cities. The nodes in this level have low connections with other nodes and are located at the edge of the network, which forms an extremely unbalanced development pattern on the core.
4.3.2. Work Stage (Figure 2). (1) Core layer: Beijing. Beijing is firmly at the core and highest level of the network. As an important economic, educational, and cultural center of China, Beijing is very attractive to high-level talents. (2) Subcore layer: Shanghai, Nanjing, Tianjin, Guangzhou, Hangzhou, Wuhan, Xi'an, and Hong Kong. The subcore cities are the more important nodes in the network. Most of these cities are located in coastal areas, with developed economy, high education level, superior working environment, and suitable natural environment. These cities have created good conditions for the influx of talent and become the main influx destination of talents. Although Wuhan and $\mathrm{Xi}$ 'an are located in the central and western regions, 

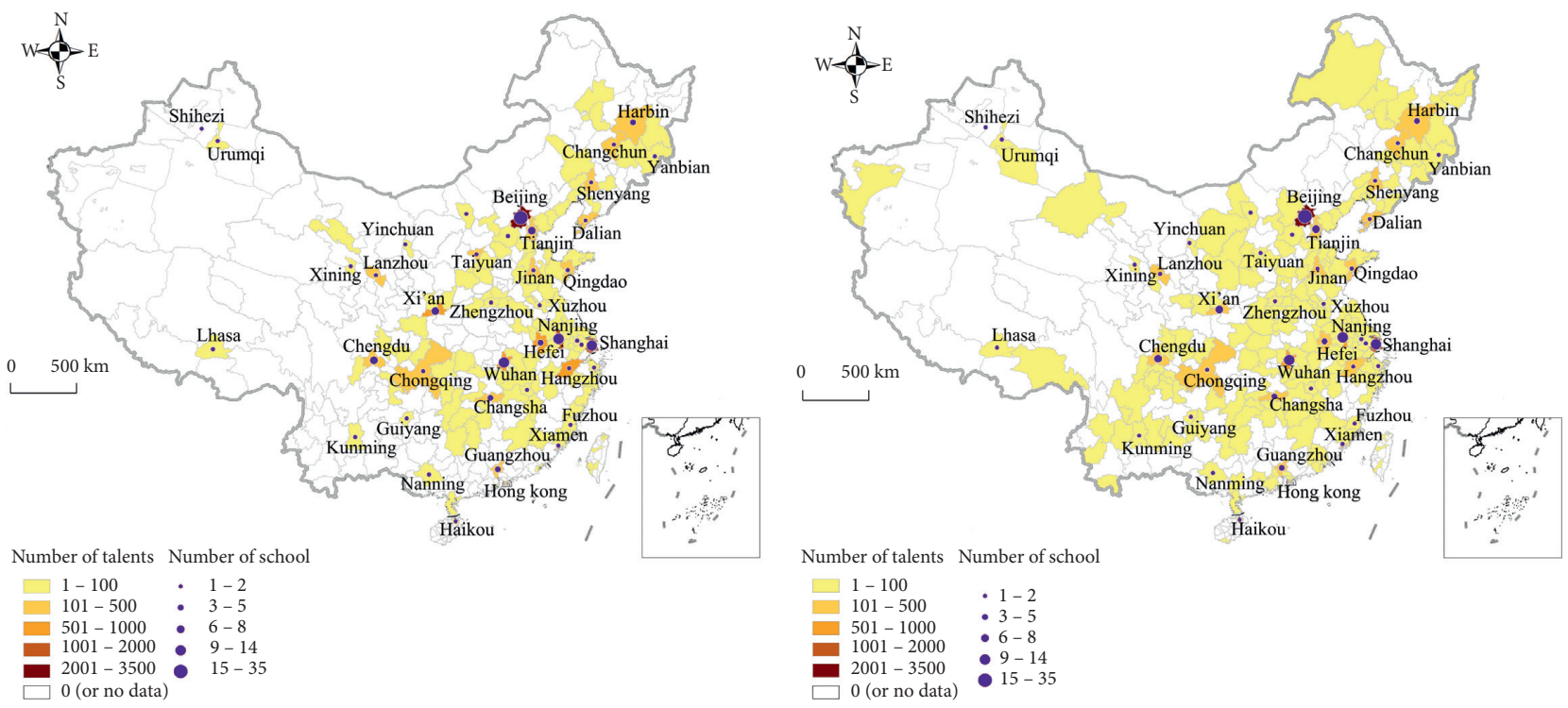

Figure 4: The spatial distribution map of China's high-level talents 985 and 211 universities.
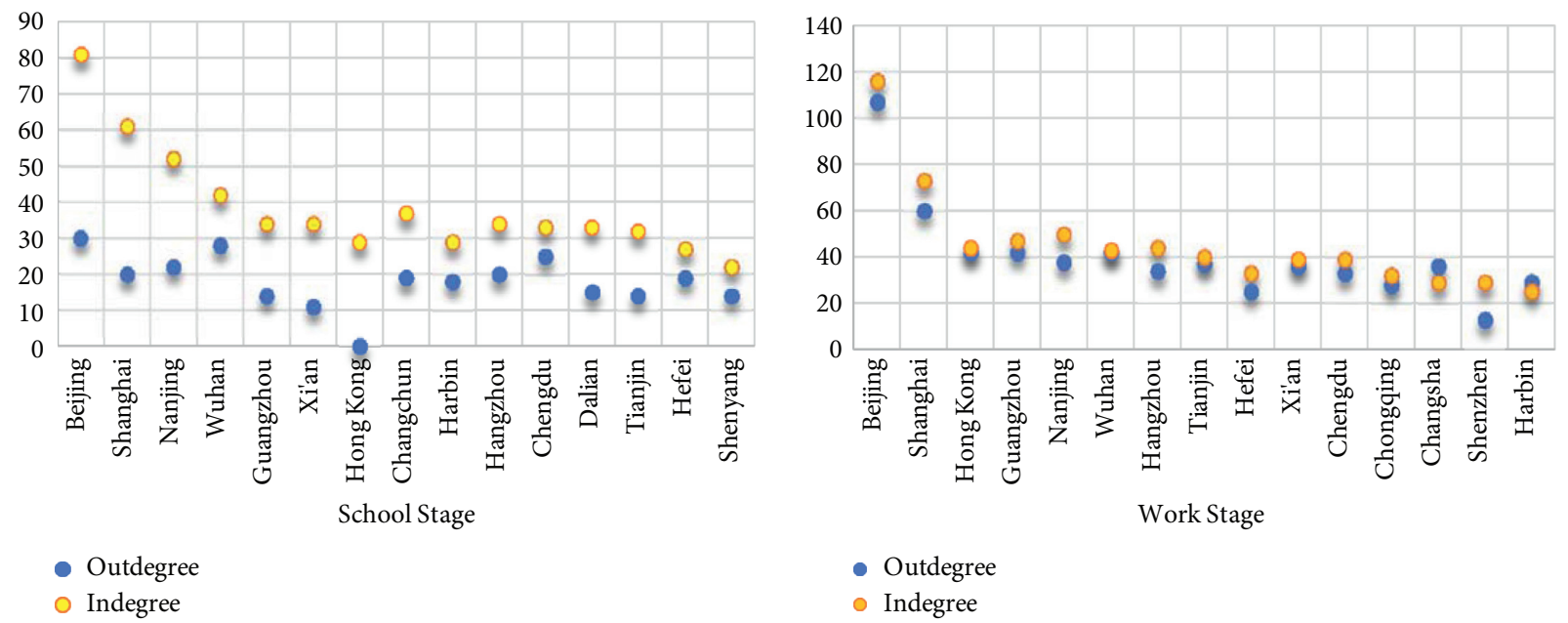

- Outdegree

○ Indegree

- Outdegree

Figure 5: Node degree centrality at different stages. Note: only the top 15 nodes with degree centrality are displayed.

respectively, the two cities are not only provincial capitals but also gateway cities in the central and western regions. They also have a large number of scientific research platforms and profound cultural heritage. Therefore, it has also attracted a large influx of talents and has become a secondary core. (3) Subedge layer: Lanzhou, Xiamen, Taipei, Hefei, Harbin, Dalian, Chengdu, Kunming, Shenyang, Jinan, Shenzhen, Zhengzhou, Chongqing, Changchun, Changsha, and Qingdao. The flow of talent at this level has been significantly reduced, and the number of cities has increased significantly, and most of them belong to provincial capital cities or provincial central cities. Among them, the status of Shenzhen in the network has been greatly improved compared to the status of education. Shenzhen's low status in the talent mobility network may be due to the fact that it is an emerging innovation center. The number of top universities, scientific research institutions, and national laboratories in
Shenzhen in the early days was small, and the influx of talent was little. With the accelerated flow and integration of innovative elements such as high-tech industries, capital, and technology, Shenzhen is gradually building into an international scientific and technological innovation center, and it will certainly attract a steady flow of high-level talent. (4) Edge layer: Sanya, Sanming, Shangrao, Dongguan, Dongying, and other 188 cities. This level of network node has the lowest status, and a large number of talents flow to the core and subcore layers.

From the perspective of change, the core of China's highlevel talent mobility network is always Beijing. The subcore level has changed a lot. During the education stage, Chengdu, Changchun, and Changsha were in the subcore level, but in the working stage, these three cities have already withdrawn from this level. Tianjin, Guangzhou, Hangzhou, and Hong Kong have been upgraded from the original 
(1) School Stage

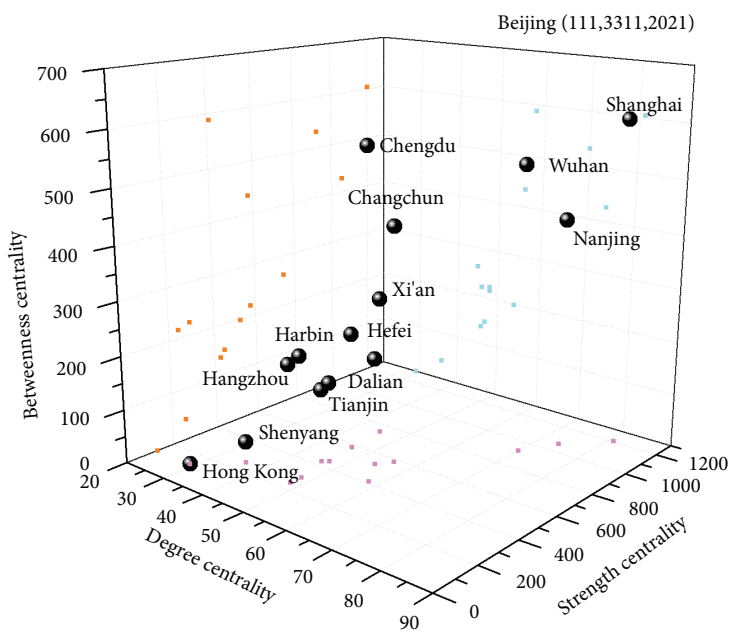

- Projection of Degree centrality and Strength centrality

- Projection of Degree centrality and Betweenness centrality

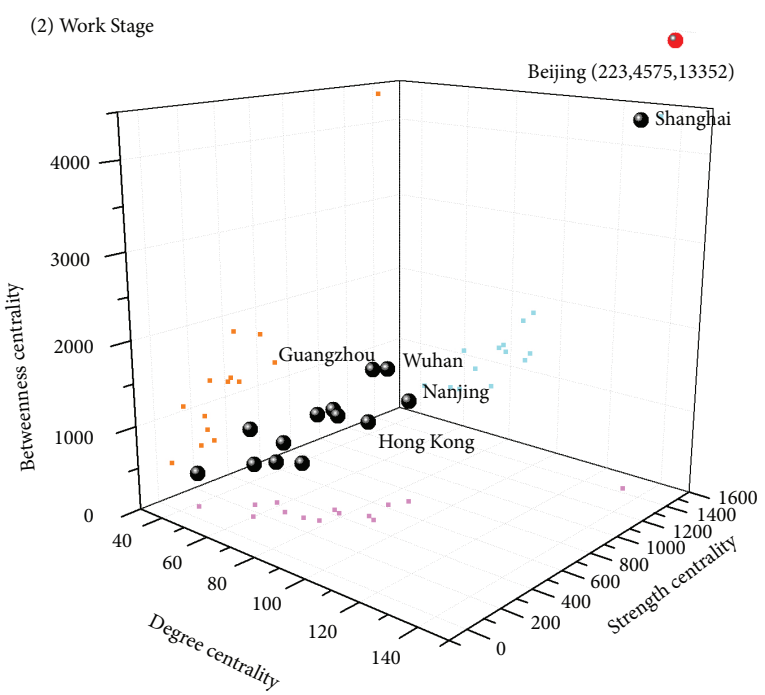

- Projection of Strength centrality and Betweenness centrality

FiguRE 6: Centrality of network nodes. Note: only the top 15 nodes of comprehensive centrality are shown in the figure. Because Beijing has a high centrality and affects the visualization of the results, it is listed separately. (a) School stage. (b) Work stage.

subedge level to the subcore level. This situation may have a great relationship with the distribution of educational resources in China. The overall subedge layer has not changed much, while the number of nodes in the edge layer has increased.

4.4. Spatial Structure of the Network. At the stage of school, the network space structure showed a "small quadrangular pyramid structure" with Beijing as the apex and Xi'an, Wuhan, Shanghai, and Nanjing as the base (Figure 3). This structure is not only related to the distribution of national educational resources but also related to the region itself. For example, Xi'an is the center of the western region, and talents in the western region tend to flow to Xi'an. The talent flow in the network is mainly concentrated on Shanghai, Nanjing, Wuhan, Xi'an, Hefei, and other cities. Beijing, Shanghai, and Guangzhou are major cities with both inflow and outflow of talent, and in general the inflow is greater than the outflow. Cities such as Wuhan, Nanjing, Hefei, Xi'an, Changchun, and Harbin are dominated by the outflow of talent. The city pairs with the largest flows are as follows: Wuhan-Beijing, Nanjing-Beijing, Xi'an-Beijing, Hefei-Beijing, Beijing-Shanghai, and Changchun-Beijing.

During the work stage, the network space structure was upgraded and expanded, showing a "large quadrangular pyramid structure" with Beijing as the apex and Xi'an, Chengdu, Guangzhou (Hong Kong), and the Yangtze River Delta region (Shanghai, Nanjing) as the base (Figure 3). The entire spatial structure expands to the Guangdong, Hong Kong, and Macao regions in southeastern China. The city pairs with the largest flows are as follows: Beijing-Shanghai, Beijing-Hong Kong, Shanghai-Beijing, Hong Kong-Beijing,
Beijing-Wuhan, and Beijing-Guangzhou. Talents' choice of workplace is related to the city in which they were educated. However, the scope and number of talents flowing during the work stage is still expanding to the coastal cities in the southeast.

Comparing the changes in the structure of the talent mobility network in the two stages, it is found that the network is expanding to the southeast, and the status of the city nodes in the southern part of the network is constantly increasing. Take Guangzhou as an example. In the education stage, Beijing and Guangzhou are less connected, while the flow of talent between Beijing and Guangzhou at the work stage has greatly increased. In recent years, Guangzhou has continuously introduced policies to attract talent. From 2016 to 2020 alone, Guangzhou has invested a total of 3.5 billion yuan in finance to focus on cultivating and introducing 500 leading talents in innovation and entrepreneurship. In addition, 500,000 to 5 million, up to 30 million salary subsidies will be given to outstanding industrial talent and high-level talent, and the team of leading entrepreneurs and talents will be supported in various ways. The superior talent policy attracts the continuous inflow of talent. According to the data in this paper, the current high-level talent in Guangzhou has reached 291. The influx of talent can enhance Guangzhou's position in the talent mobility network. With the exchange, diffusion, and accumulation of knowledge, technology, and information among talents, Guangzhou's innovation cooperation and innovation capabilities will continue to be strengthened, and it can also enhance the city's innovation network influence. While the network is extending to the southeast, the connection structure between cities in the Northeastern region and Beijing has been weakening. In particular, Beijing's ties with 
Changchun have decreased the most. It can be seen that the Northeast region is unable to retain talent well and is in a disadvantaged position in the talent mobility network as an important talent training area.

\section{Discussion}

Based on China's HLT flow data, this paper constructs HLT flow networks in the two stages of school and work, abstracts the actual flow of talent into an analyzable and operable digital matrix, and uses complex network analysis methods to carry out related research and analysis. Comparative analysis found that the spatial distribution of HLT in China has a trend of "large dispersion and small aggregation." The gap between the centrality of nodes in the network has narrowed.The flow of talents has become more frequent and complicated. The core-peripheral structure of the network has not changed much, and the Matthew effect of the flow of talents still exists. From a spatial perspective, the talent flow network has significant spatial heterogeneity and continues to expand southward.

\subsection{Changing Characteristics of the Spatial Distribution of} Talents. As talents moving from the education stage to the work stage, their spatial distribution shows changed characteristics of "large dispersion and small gathering." "Large dispersion" is mainly manifested in the obvious increase in the number of cities where talents are distributed during the work stage. Some non-first-tier and nonprovincial capital cities in the central and western regions are also destinations for talent choices. HLT are distributed in second- and thirdtier small cities due to the following reasons: first, it is related to the geographical distribution of work platforms. The establishment of some of the top domestic colleges and universities is affected by historical accumulation, administrative planning, and other nonmarket factors. They are located in the central and western regions. Second, it has a greater relationship with national and local policies. When implementing the policy of attracting talents, the country will also take efficiency and fairness into account and give full consideration of the coordinated development of the region. The "Outline of the National Medium and Longterm Talent Development Plan (2010-2020)" proposes to establish and improve a regional talent exchange and cooperation mechanism that is compatible with the development of the western region, the revitalization of old industrial bases in the northeast, the rise of the central region, and the development strategy of the eastern region. In the process of implementation, localities also attract talents through flexible methods such as building academician workstations and setting up part-time professors and lecture professors. The third is the balance between life pressure and personal development space [3]. High housing prices or living costs are an important obstacle for talents to stay in developed cities for a long time. Therefore, high-level talents have shown a trend of spreading across the country.

"Small gathering" is mainly reflected in the fact that talents are still gathering in a few eastern first-tier cities and provincial capitals [51-53]. Beijing, Tianjin, and Shanghai are hot spots for talent distribution [50]. This is mainly due to the rapid economic development in the eastern part of China, as well as the better conditions in scientific research, education, life, job opportunities, platforms, and prospects $[8,50,54,55]$. Provincial capital cities such as Wuhan and Hefei in the central part also have a number of first-class universities and scientific research institutes, and there are more talents who choose to work in central cities $[56,57]$. The western region is far lower than the eastern region in terms of economic development, employment environment, and talent introduction policies, which resulted in fewer talents to work. This phenomenon also reflects that the distribution of human resources does not completely overlap with educational resources. For example, Lanzhou, as a top talent training city, has 319 talents who choose to go to Lanzhou University for education, but only 150 talents choose to work in Lanzhou.

5.2. Bidirectional, Sticky, and Matthew Effect of HLT Flow. Through comparative research, it is found that the flow of HLT between cities in the school stage is agglomerating, mainly in a few cities such as Beijing and Shanghai. The flow of talents at the work stage has a significant bidirectional characteristic. That is, some cities are not only the places where talents flow in but also the places where talents flow out. This finding is more consistent with the research results of Refs. [8,9], and [15]. From the spatial flow trajectory of China's HLT workplaces, we find that the flow of talents is mainly among Beijing, Shanghai, Hong Kong, and provincial capital cities. These cities are both strong inflow centers and strong outflow centers. Moreover, these cities are often developed cities with technology and economy.

The flow of HLT in China has a strong stickiness. That is, where the talents go to school and where they are employed have a strong consistency. From the talent flow data, it is known that $1,822(23.56 \%)$ talents' school locations and work locations have never changed; 2,569 (33.22\%) talents finally returned to the city where the school is located to work after experiencing a series of flows. This result is similar to the research results of Refs. [51, 58]. Although the types of talents studied are different, they show a relatively similar flow trend. That is, when choosing a working city, it is easier for talents to choose a city with academic relationships. The research of Refs. [6, 17] also found that factors such as interpersonal relationships established during school and a high degree of familiarity with the surroundings enhanced their tendency to find employment near the place of study. Of course, there are also significant regional differences in the stickiness of high-level talent flow. Cities with strong stickiness are mainly located in the southeast coastal area, the middle and lower reaches of the Yangtze River, and provincial capital cities. This result shows the significance of the overall stickiness of the superior area to the formation of talent highlands [51].

The Matthew effect still exists in the flow of HLT in China. That is, the more talented places are, the more attractive to talents, and the more talents they can get; the less 
talented places, the less attractive to talents, they will lose more talents, where are at a disadvantage in the talent competition [59]. In this study, this effect is mainly manifested in the talent flow network controlled by a small number of core nodes, and most of the talent flow is still concentrated in a few core cities. By comparison, it is found that the core-edge structure of the network in the school stage and the work stage is very significant and similar. From education to work, the network nodes at the subcore layer and the subedge layer have changed significantly. In the network, the core city Beijing will continue to strengthen and consolidate its core position by attracting resources from other levels of the network. In the subcore layer, cities such as Chengdu, Changsha, and Changchun withdrew, while cities such as Hangzhou, Tianjin, and Hong Kong entered. It not only reflects the difference between talents' preference for education cities and work cities but also reflects cities at the subcore and subperipheral levels can continuously strengthen their own investment, enhance their economic and innovative capabilities, and achieve a leap to a higher level. The marginal cities are still in a state of transporting talents to other levels for a long time due to their weak strength.

\subsection{Spatial Heterogeneity of the HLT Flow Network.} Through comparative analysis, it is found that the spatial heterogeneity of China's HLT flow network at the work stage is more significant. At the school stage, the flow of talents is mainly among cities with abundant education resources. At the work stage, the trend of regional concentration of talent mobility in China is more obvious. Talents mainly gather in the Beijing-Tianjin-Hebei, Yangtze River Delta, Wuhan metropolitan area, Chengdu-Chongqing urban agglomeration, and the Guangdong-Hong Kong-Macao Greater Bay Area. Among them, the talent flow network is expanding to the Guangdong-Hong Kong-Macao Greater Bay Area in southeastern China. With the continuous implementation of regional development strategies such as the GuangdongHong Kong-Macao Greater Bay Area, it may stimulate the continued flow of talents to the region. Cities such as Guangzhou, Shenzhen, and Hong Kong will continue rising in their roles as talent-absorbing places. Moreover, the heterogeneity of China's HLT flow at different stages is also greatly related to the distribution of the country's education and science centers. It can be said that the formation and transfer of education centers and technology centers will inevitably be accompanied by the flow of talents. On November 8, 2020, the Chinese Academy of Social Sciences and China Times jointly released the " 2020 National Central City Index" report (https://baijiahao.baidu.com/s?id=168275848 $0360564512 \& w f r=s p i d e r \& f o r=p c)$. The report ranks China's education center cities and identifies Beijing, Shanghai, Nanjing, Xi'an, Wuhan, Guangzhou, Chengdu, and Changsha as the country's education center cities. This ranking is almost the same as the ranking of cities with HLT in the school stage, which further proves that high-level talents are more inclined to flow into cities with rich educational resources during the education stage. In March
2021, the 14th Five-Year Plan for the National Economic and Social Development of the People's Republic of China and the 2035 long-term goal outline (http://www.gov.cn/xinwen/ 2021-03/14/content_5592884.htm) were released, pointing out to support Beijing, Shanghai, and the Guangdong-Hong Kong-Macao Greater Bay Area to form an international science and technology innovation center, and to construct comprehensive national science centers in Beijing-Huairou and Shanghai-Zhangjiang, the Greater Bay Area, and AnhuiHefei as well as to support the construction of regional science and technology innovation centers in places where conditions permit. The spatial distribution of these technological innovation centers is very consistent with the regional concentration of talent flow during the work phase, which shows that there is a close relationship between the two.

\section{Conclusion}

The flow of talents has always been highly concerned by scholars and the government. At present, China is in the most active period of cross-regional flow of HLT. This research conducted a comparative study on the current status of China's HLT flow and its network structure during the school and work stages, and the following conclusions were reached.

First, comparative analysis found that the spatial distribution of HLT in China has a trend of "large dispersion, small agglomeration." The distribution of talents in the school stage is more consistent with the spatial distribution characteristics of the country's educational resources, while the work stage is mainly concentrated in cities with better economic development and clusters of innovative platforms and does not completely coincide with the distribution of educational resources.

Second, from school to work stage, the flow of talents becomes more active and the scope of mobility continues to expand. At the school stage, China's HLT mainly gather in cities with rich educational resources such as Beijing and Shanghai. At the work stage, talents are more inclined to flow into eastern coastal cities and provincial capitals. In addition, the flow of talents at the work stage has a significant bidirectional characteristic of flow between firsttier cities or provincial capital cities. At the same time, some advantageous regions also have strong stickiness to talents.

Third, the core-edge structure of the network in the two stages is significant. The core layer is Beijing, and the subcore and subedge layer cities have changed. The core-edge structure of the two stages shows relatively similar characteristics. That is, cities with high economic levels, rich educational resources, complete innovation infrastructure, and high-level technology are at the core of the talent flow network. Most non-first-tier and nonprovincial capital cities are at the marginal level. Moreover, the Matthew effect of talent flow has always existed.

Fourth, the spatial structure of the network has been upgraded and expanded, from the "small quadrangular pyramid" structure with Beijing as its apex and Xi'an, 
Wuhan, Shanghai, and Nanjing as its base, to Beijing as its apex, Xi'an, Chengdu, and Guangzhou (Hong Kong), the Yangtze River Delta (Shanghai, Nanjing) as the base of the "large quadrangular pyramid" structure. At the work stage, the flow of talents shows obvious spatial heterogeneity, and the trend of regional concentration of talents is more obvious.

From the perspective of urban development, the higher the position of a city in the talent flow network, the more talent resources it can attract from the network, as well as the capital, knowledge, and technology resources that talents can bring. The city's high-level talent matching, overall creative ability and level, high-end level, and innovation benefits will directly determine the city's status in national competition and industrial division of labor. However, by comparing and analyzing the characteristics of the talent flow in the two stages, we find that in cities with weak economic strength, the educational advantage cannot be transformed into a technological advantage and an economic advantage, which will lead to brain drain. In this case, the government needs to consider reducing the barriers to talent introduction through more flexible methods such as precise introduction of talents, flexible introduction of talents (intellectual introduction, academic part-time job, and talent dispatch), etc., when its own human resources cannot be better reserved. By strengthening the connection with the human resources of other cities, forming a cross-regional cooperation network, and using the resource exchange in the network, these are also ways to minimize the disadvantages caused by the brain drain.

Based on the growth stage of talents, this paper studies the spatial distribution and talent flow network of China's HLT, trying to enrich the current research on talent mobility and even talent geography in China. However, this article still has some shortcomings. In the future, we will continue to improve relevant theoretical analysis, try to build a multiscale, multiconnotation regional talent mobility network, and explore the impact of regional talent mobility and the formation of the network on regional economic and technological development, so as to provide targeted and operable policy recommendations for national or regional talent policies and innovative development.

\section{Data Availability}

The data used to support the study can be available upon request.

\section{Conflicts of Interest}

The authors declare that they have no conflicts of interest.

\section{Acknowledgments}

This research was supported by the "Strategic Priority Research Program of the Chinese Academy of Sciences" (No. XDA20010103).

\section{References}

[1] J. Xi, "Speech at the teacher-student symposium of Peking University," 2018, http://www.chinadaily.com.cn/a/201805/ 08/WS5af0f499a3105cdcf651c7\%20fc.html.

[2] A. Geuna, Global Mobility of Research Scientists, Elsevier Monograph, Amsterdam, Netherlands, 2015.

[3] China Science Coordination Research Propaganda Department, The Total Amount, Structure And Flow Of Scientific Research Personnel Of Scientific And Technological Human Resources, vol. 6, Tsinghua University Press, Beijing, China, 2021.

[4] Y. Wang, H. Luo, and G. Yang, "Global features and evolution of talent mobility with complex network between provinces in China," Science Research Management, Available at: https:// kns.cnki.net/kcms/detail/11.\%201567.G3.20210914.1328.005. html, 2021.

[5] Y. Li and J. Liu, "The practice and prospect of the construction of scientific and technological talent team in China since the reform and opening-up," Human Resource Development of China, vol. 35, no. 11, pp. 30-43, 2018, (in Chinese).

[6] Y. Jiang, X. Wang, and R. Ma, "Theoretical exploration of innovative talent agglomeration: from the perspective of city selection of global talent flow," Scientia Geographica Sinica, vol. 41, no. 10, pp. 1802-1811, 2021, (in Chinese).

[7] H. Huang and Y. Qu, "Peacock flying to Southeast: economic transformation and star scientist mobility," Journal of Huazhong University of Science and Technology (Nature Science Edition), vol. 33, no. 3, pp. 63-72, 2019, (in Chinese).

[8] Y. Zhou, Y. Guo, and Y. Liu, "High-level talent flow and its influence on regional unbalanced development in China," Applied Geography, vol. 91, no. 91, pp. 89-98, 2018.

[9] L. Zhou and Y. Zhang, "The spatial distribution and flow trends of Chinese top academic talents: based on the case study of academicians of Chinese academy of sciences," Geographical Research, vol. 38, no. 7, pp. 1749-1763, 2019, (in Chinese).

[10] Y. Liu, J. Shen, and W. Xu, "From school to university to work: migration of highly educated youths in China," The Annals of Regional Science, vol. 59, no. 3, pp. 651-676, 2017.

[11] H. Gu, X. Meng, T. Y. Shen, and L. Wen, "China 's highly educated talents in 2015: patterns, determinants and spatial spillover effects," Applied Spatial Analysis and Policy, vol. 13, no. (2), 2020.

[12] H. Gu, F. Rowe, Y. Liu, and T. Shen, "Geography of talent in China during 2000-2015: an eigenvector spatial filtering negative binomial approach," Chinese Geographical Science, vol. 31, no. 2, pp. 297-312, 2021.

[13] Y. Liu and J. Shen, "Modelling skilled and less-skilled interregional migrations in China, 2000-2005," Population, Space and Place, vol. 23, no. 4, pp. e2027.1-e2027.17, 2017.

[14] H. Huang and J. Lian, "Does job mobility improve scientists" academic productive?" Tsinghua Journal of Education, vol. 41, no. 5, pp. 127-135, 2020, (in Chinese).

[15] Z. Gao, C. Zhong, C. Wang, and Y. Liu, "Analysis on the flow of high-level scientific and technological talents in China: taking the sponsor of national science fund for distinguished young scholars as example," Bulletin of National Natural Science Foundation of China, vol. 33, no. 4, pp. 363-366, 2019, (in Chinese).

[16] D. Shi and Z. Zhang, "Talent programs and scientists' professional mobility: a case study of China jiang scholars," Document, Information \& Knowledge, no. 2, pp. 42-50, 2020, (in Chinese). 
[17] L. Rui, D. Wu, J. Bao, Y. Qiu, and W. Wang, "Evolution of temporal and spatial pattern and driving mechanisms of agglomerative growth of senior science talents a case study of academicians of CAS," Progress in Geography, vol. 32, no. 7, pp. 1123-1138, 2013, (in Chinese).

[18] M. Castells, The Rise of the Network Society, Wiley-Blackwell, Hoboken, NJ, USA, 2000.

[19] M. Castells, The Informational City: Information Technology, Economic Restructuring and the Urban-Regional Progress, Blackwell, Oxford, UK, 1989.

[20] M. Castells, "Grassrooting the space of flows," Urban Geography, vol. 20, no. 4, pp. 294-302, 1999.

[21] H. Ma, "The theoretical construction and network simulation of intercity innovative relationships in knowledge flow space," Acta Geographica Sinica, vol. 75, no. 4, pp. 708-721, 2020, (in Chinese).

[22] P. J. Taylor, World Cities Network: A Global Urban Analysis, Routledge, London, UK, 2004.

[23] E. J. Malecki, "Hard and soft networks for urban competitiveness," Urban Studies, vol. 39, no. 5, pp. 929-945, 2002.

[24] R. Florida, C. Mellander, K. Stolarick, and A. Ross, "Cities, skills and wages," Journal of Economic Geography, vol. 12, no. 2, pp. 355-377, 2012.

[25] D. J. Watts and S. H. Strogats, "Collective dynamics of 'smallworld' networks,” Nature, vol. 393, no. 6684, pp. 440-442, 1998.

[26] A. L. Barabási and R. Albert, "Emergence of scaling in random networks," Science, vol. 286, no. 5439, pp. 509-512, 1999.

[27] Y. Wang, H. Luo, and Z. Li, "The complex international migration network for top scientific and technological talents," International Journal of Humanities and Social Science, vol. 7, no. 10, pp. 133-142, 2017.

[28] R. Pastor Satorras and A. Vespignani, Handbook of graphs and networks: from the genome to the Internet, Chapter Epidemics and Immunization in Scale-Free Networks, Wiley-VCH Verlag GmbH \& Co., KGaA, Weinheim, Germany, 2002.

[29] F. Jin, "A study on network of domestic air passenger flow in China," Geographical Research, vol. 20, no. 1, pp. 31-39, 2001, (in Chinese).

[30] W. Gu and H. Liu, "Spatial structure, hierarchy and formation mechanisms of scientific collaboration networks: evidence of the belt and road regions," Chinese Geographical Science, vol. 30, no. 6, pp. 959-975, 2020.

[31] M. Chen, X. Luo, M. Hu, and X. Zhang, "Club characteristic and the proximity effect of travel links between cities in China," Complexity, vol. 2020, Article ID 5786384, 13 pages, 2020.

[32] X. Luo and M. Chen, "Urban network of China from the perspective of population mobility: three-dimensional coo44ccurrence of nodes and links," Environment \& Planning A, vol. 53, no. (5), pp. 887-889, 2021.

[33] Y. Zhu, X. Zheng, and Y. Zhang, "Analysis on the flowing rules of creative talents in science and technology in China- an empirical research based on leading talents in science and technology of national ten thousand talents program," Forum on Science and Technology in China, no. 3, pp. 166-173, 2020, (in Chinese).

[34] W. Shi, W. Yang, and D. Du, "The scientific cooperation network of Chinese scientists and its proximity mechanism," Suatainability, vol. 12, p. 660, 2020.

[35] D. Duan, D. Du, Q. Gui, and L. H. Duan, "The geography of Chinese entrepreneurial development," Human Geography, vol. 33, no. 4, pp. 102-112, 2018, (in Chinese).
[36] P. Zhu, Y. Zhang, W. Cao, Y. Ren, and Y. Jiang, "Spatial distribution and geographical mobile network of enterprise management talents in Yangtze river delta: based on the data of senior executive director team of listed company," Human Geography, vol. 35, no. 4, pp. 121-129, 2020, (in Chinese).

[37] E. M. Vogtle and M. Windzio, "Networks of international student mobility: enlargement and consolidation of the European transnational education space?" Higher Education, vol. 72 , no. 276, pp. 1-19, 2015.

[38] H. Ma, F. Zhang, and Y. Liu, "Transnational elites enhance the connectivity of Chinese cities in the world city network," Environment \& Planning A, vol. 50, no. 4, pp. 749-751, 2018.

[39] G. Fagiolo and M. Mastrorillo, "International migration network: topology and modeling," Physical Review E - Statistical, Nonlinear and Soft Matter Physics, vol. 88, no. 1, Article ID 012812, 2013.

[40] Y. Wang, H. Luo, and Z. Li, "A study on the network of global mobility of scientific top talents - based on bibliometrics and complex network," Technology and Innovation Management, vol. 39, no. 5, pp. 521-529, 2018, (in Chinese).

[41] Y. Wang and H. Luo, "Global talent mobility from 1990-2012 according to patent data," China Soft Science Collection 2019 China Soft Science Essays, (in Chinese), p. 10, China Soft Science Research Association, Beijing, China, China Soft Science Research Association, 2020.

[42] J. V. Beaverstock, "Skilled international migration: an analysis of the geography of international secondments within large accountancy firms," Environment \& Planning A, vol. 23, no. 8, pp. 1133-1146, 1991.

[43] J. V. Beaverstock, "The spatial mobility of corporate knowledge," Expatriation, Global Talent, and the World City// Mobilities of Knowledge, Springer International Publishing, New York, NY, USA, 2017.

[44] S. Chen, Introduction to Innovative Talents, Sun Yat-sen University press, Guangzhou, China, (in Chinese), 2015.

[45] J. Qiao and X. Chen, "Dose mobility of high-lecel talents affect academic production? taking the field of life sciences as an example," Universities and Disciplines, vol. 2, no. 3, pp. 91107, 2021, (in Chinese).

[46] J. Liu, "Whole Network Analysis," UCINET Software Practical Guide, Gezhi Publishing House, Shanghai People's Publishing House, Shanghai, China, (in Chinese), 3rd edition, 2019.

[47] C. Hou, D. Du, C. Liu, Q. Gui, S. Liu, and X. Qin, "Spatiotemporal evolution and factors influencing international student mobility networks in the world," Acta Geographica Sinica, vol. 75, no. 4, pp. 681-694, 2020, (in Chinese).

[48] C. Liu, Q. Gui, D. Duan, and M. Yin, "Structural heterogeneity and proximity mechanism of global scientific collaboration network based on co-authored papers," Acta Geographica Sinica, vol. 72, no. 4, pp. 737-752, 2017, (in Chinese).

[49] C. Hou, D. Du, C. Liu, and C. Zhai, "Spatiotemporal evolution of global talent mobility network based on the data of international student mobility," Geographical Research, vol. 38, no. 8, pp. 1862-1876, 2019, (in Chinese).

[50] R. Wang, H. Xu, and D. Xue, "Spatio-temporal change of facaulty members of higher education institute and its influential factors in China in 2005-2015," Scientia Geographica Sinica, vol. 39, no. 8, pp. 1199-1207, 2019, (in Chinese).

[51] J. Nie and H. Liu, "Spatial pattern and the resulting characteristics of talent flows in China," Scientia Geographica Sinica, vol. 38, no. 12, pp. 1979-1987, 2018, (in Chinese).

[52] P. Zhang, Y. Zhao, and Y. Ma, "Intellectual resources development and regional competitiveness of northeast China," 
Scientia Geographica Sinica, vol. 23, no. 5, pp. 513-518, 2003, (in Chinese).

[53] J. Zhang, D. B. Du, and H. N. Jiang, "Regional differences of S\&T talents in jiangsu province," Scientia Geographica Sinica, vol. 31, no. 3, pp. 378-384, 2011, (in Chinese).

[54] Y. Liu, J. Shen, and Y. Liu, "Transnational mobility of the highly skilled: a review," Human Geography, vol. 28, no. 2, pp. 7-12, 2013, (in Chinese).

[55] H. Ma and F. Zhang, "Literature review on the impetus and influence of talents mobility between countries and regions," Economic Geography, vol. 39, no. 2, pp. 40-47, 2019, (in Chinese).

[56] X. Jiang, W. Fu, and G. Li, "Can the improvement of living environment stimulate urban innovation? - analysis of highquality innovative talents and foreign direct investment spillover effect mechanism," Journal of Cleaner Production, vol. 255, pp. 120-138, 2020.

[57] R. Ma, "Constructing the creative space and evolving perspectives on cities," Urban Planning Forum, vol. 54, no. 6, pp. 109-118, 2010, (in Chinese).

[58] Y. Wang, C. Cui, Q. Wang, Y. Ning, and Z. Yang, "Migration of human capital in the context of vying for talent competition: a case study of China's "first-class" university graduates," Geographical Research, vol. 40, no. 3, pp. 743-761, 2021.

[59] X. Yuan, Study on Behavior and Effects of Creative Talents' Agglomeration from the View of Complex Adaptive System, Donghua University, Shanghai, China, 2017. 